\title{
Renta básica universal: Garantizar la existencia ciudadana
}

\section{Universal basic income: Guarantee the existence of citizens}

\author{
Daniel Raventós \\ UNIVERSITAT DE BARCELONA
}

\section{RESUMEN}

La renta básica universal explota en cuanto a conocimiento a partir de la pandemia y los distintos confinamientos. Esto también ha provocado que haya confusión porque hay gente que se ha referido a subsidios condicionados como si fueran la renta básica, lo cual ha incrementado esta confusión. Entonces, es importante definir qué es la renta básica.

Palabras clave: Renta básica universal, subsidios, impuestos, libertad, renta máxima

\begin{abstract}
Universal basic income exploits in terms of knowledge from the pandemic and the various confinements. This has also caused confusion because there are people who have referred to conditional subsidies as basic income, which has increased this confusion. So, it's important to define what basic income is.
\end{abstract}

Keywords: Universal basic income, subsidies, taxes, freedom, maximum income

danielraventos@ub.edu 
Qué es la Renta Básica

s cierto que con la crisis del covid, el debate por la renta básica universal se ha disparado. Un editorial del Financial Times, al inicio de la pandemia, decía que propuestas hasta ahora excéntricas como la propuesta de renta básica incondicional o el impuesto a las grandes fortunas, pronto deberían ser contempladas. Esto no es especial, pero si es especial que lo mencione el Financial Times.

La renta básica explota en cuanto a conocimiento a partir de la pandemia y los distintos confinamientos. Esto también ha provocado que haya confusión porque hay gente que se ha referido a subsidios condicionados como si fueran la renta básica, lo cual ha incrementado esta confusión. Entonces es importante definir qué es la renta básica. Según la Basic Income Earth Network (BIEN): es una asignación pública monetaria incondicional y universal. Es una definición corta pero que cada palabra de la definición tiene mucha importancia.

La Renta Básica es monetaria porque estamos hablando de dinero y no de especies. Es pública porque se financia mediante una reforma fiscal que debe hacer la administración pública. Pero las palabras que definen mejor a la renta básica y que son las más polémicas entre quienes están en contra de la renta básica, y al mismo tiempo, las que tienen más virtudes para quienes somos defensores, son la incondicionalidad y la universalidad. La mejor manera de ver la incondicionalidad es comparando los subsidios que conocemos en la mayor parte del mundo, es decir, subsidios para la pobreza o para determinados niveles de renta, en cambio la renta básica no se condiciona bajo criterios, requisitos o focalización del gasto, es incondicional. Y la universalidad significa que todas las personas que vivieran dentro de una zona geográfica serían perceptoras de la renta básica.

Me gustaría explicar un poco lo de la universalidad, porque no quiere decir que todo el mundo gane. La recibe toda la población, pero como se debe financiar con impuestos progresivos, donde los que ganan más aportan más, los más ricos también reciben la renta, 
pero deben pagar más para financiarla. Todos reciben la renta básica, pero no todo el mundo gana.

Pero entonces, ¿̨por qué entregar la renta básica a los más ricos y no concentrar todos los esfuerzos en quienes más lo necesitan? Veamos. Cuando se establece un umbral para acceder a subsidios, aparecen dos errores: el falso positivo y el falso negativo. El primero es cuando alguien pasa la prueba de requisitos y no debería hacerlo. El falso negativo es cuando alguien no supera la prueba y debería hacerlo, lo que es más problemático. Según distintos estudios, se excluye entre el 44 a $97 \%$ de las personas que deberían ser objeto de todos estos programas de subsidios.

\section{El Debate de la Renta Básica}

También la renta básica ha confundido a mucha gente porque ha sido promovida por espectros políticos y académicos muy distintos. La renta básica la defiende gente muy de derechas y gente muy de izquierdas. Pero esto es un error, es una falsa impresión. Es cierto que algunos economistas en The Wall Street Journal o académicos neoliberales defienden la renta básica. Entonces, ¿cuál es la diferencia?

Para saber diferenciar de dónde viene la propuesta de renta básica, es muy sencillo. Y es cómo se financia la renta básica, o lo que es lo mismo, quién gana o quién pierde. Una financiación de la renta básica debe especificar qué parte de la población gana y qué parte pierde. Otra diferencia entre izquierda y derecha, es evaluar qué medidas acompañan a la renta básica, pues debe haber políticas públicas que la acompañen (políticas de vivienda, políticas monetarias, etc.), la renta básica no puede reemplazar todos los servicios que ofrece el Estado.

En un debate con Michael Tanner (CATO Institute), quedamos de acuerdo de manera muy amable que no estamos de acuerdo en nada. No estamos de acuerdo en la fundamentación de la renta básica, cómo financiarla, sobre la cantidad, para lo que debería servir...

Distintos académicos/as de áreas y disciplinas múltiples, se han interesado por la renta básica, en sus dos columnas. Las dos 
grandes columnas sobre las que se asienta la renta básica: la columna normativa y la columna práctica o de financiación. La primera es la que intenta responder a la pregunta ¿es justa la renta básica?; y cuándo la respuesta es sí, es cuando tiene sentido debatir, estudiar o proponer formas de financiación de la renta básica.

Sobre la columna normativa se han dedicado a lo largo de los últimos años autores filósofos de distintas disciplinas o de distintas teorías de la justicia. Yo vengo de una tradición filosófica y política muy determinada, que es la libertad republicana. Ésta se puede resumir de la siguiente manera: quien no tiene las condiciones materiales de existencia garantizadas no puede ser libre. Para un republicano un pobre no puede ser libre. Si las personas tienen asegurado un ingreso monetario a un nivel igual o superior de la línea de la pobreza, entendida de manera amplia, entonces poseen un nivel sobre el cual las personas se podrían desarrollar libremente. También somos cada vez más los que defendemos la renta máxima. La riqueza y la propiedad privada son un producto esencialmente político y social, una república democrática debe ser capaz de diseñar algunos instrumentos -como una renta máxima- que eviten que riqueza y propiedad queden concentradas en unas pocas y confiscatorias manos. Las grandes riquezas amenazan la libertad de la inmensa mayoría.

Fecha recepción: 1 de junio de 2020

Fecha aceptación: 15 de julio de 2020

Versión final: 1 de septiembre de 2020 